broth, is the only food allowed during the active treatment, not more than a small teacupful every four hours; the nauseatiog effect of the ipecacuanha generally sufficiently limits the appetite. Such is the course of dysentery, in most cases, that apply for relief within the first three or four days. If the treatment be commenced later there is some danger of the disease running on to ulceration. When this has happened ipecacuanha, unless it be in one or two grain doses, is no longer useful. The time has come for the large enema and the bael fruit. The quinine mixture, with opium, just mentioned, also answers well in this stage, but I seldom give it if bael can be procured. Other drags might also be named as substitutes for bael, and one of the best is tannic acid. The large enema may at first consist of simple water, but if improvement is not very marked, after two injections, I add to it alum, in the proportion of one grain to the ounce. Once a day is often enough for this remedy, as it is rather a tax upon the patient's strength. The evening is the best time, one or two grains of opium being given by the mouth, and the small enema by the rectum, as soon as the large one comes away. From this, good rest is obtained at night, and if another small enema be given in the early morning, there will perhaps be complete quietude of the bowels till the injection is repeated the following evening. If the evacuations (including the fluid of the large enema when passed away) be carefully examined every day, while they are being slowly poured from one vessel to another, the amount of benefit is readily ascertained, as well as from the appearance of the patient and the diminished frequency of his pulse. After a variable time solid freces are discovered, and the products of ulceration are no longer found. The enemata may now be discontinued, and the opium by the mouth gradually reduced. The ba 1 should be perstvered with for an indefinite time, as it is a useful tonic to the mucous membrane, and a regulator of the alvine evacuations. ${ }^{4}$ The return to ordinary diet must in all cases be slow and cautious. I have generally found my patients able to eat a little tender meat before they could venture upon vegetables, of which latter the bael supplies the place, and this remedy is particularly advantageous when there is any scorbutic taint. ${ }^{5}$

The treatment $I$ have just described is that which $I$ have been accustomed to use for adult males. For delicate women or younger persons the doses of ipecacuanha and other things must be proportionally smaller. Fifteen or even ten grains of ipecacuanha I have often found sufficient for women. Fur children about thirteen months old, three or four grains of ipecacuanha with half a grain of compound kino powder act quite as favourably as the larger doses upon adults. Teething is often a powerful factor in these little patients, and great relief may be afforded by lancing the gums. Ia my experience the ipecacuanha treatment has not answered well in children much under a year. Up to ten months, at any rate, they do not bear well the nausea and starvation it involves. Children that are nursed, however, are not very liable to severe dysentery; it is the hand-fed children that give trouble. Up to about ten months I have found calomel answer better than ipecacuanha. For mild cases very small doses are sufficient, and an enema containing one or two minims of tincture of opium. In tha more severe cases half a grain of calomel may be given, morning and evening, to a cnild eight or ten months old, and the enema twice in twenty-four hours. I have never found leeches necessary for a child, nor have I ever had to treat children in the stage of ulceration, as they have always recovered or succumoed before this has been reached. In young children I have beea accustomed to stop all farinaceous food, and, except in infants at the breast, to limit the mik rery much, giving beef-tea or chicken broth instead.

As to the amount of opium to be given in dysentery, this must de jend upon the case. Adults will sometimes tuke an enorinous quantity without prodacing narcotiem, perha:s because it rapidly passes ont of the budy. So also with chifdren; laring berun with one or two minims in the injection the quan ity may smbtimes be increased for beyond wast a child wuatd be expected to bear.

In alwost all cases of acute as sentery, botic adults and children, I have of late yens adopt d the system above recommented of amini-tems the medicin every twelve lours. The thec of a lagge doss of jpecacuavha last fully indian Pluarmacopuia, p. 46 .

5 See Dr T F E Prown's remarks on the Indian Pharmacopoeia Indian Medical Gazette of Dec. 1 st, $107 t$, p. 800. this time, and the long interval favours rest, which is espe. cially desirable in a disease so strongly characterised by its absence. Occasionally I have departed from the system to the extent of giving four small enemata in twenty-four hours; in other cases, when the vomiting from the ipecacuanha has appeared to canse expulsion of the small enema from the rectum, I have given this in the middle of the twelve-hour period instead of at the end.

Thus far I have drawn the favourable side of the picture. Of the unfavourable cases I have little to say. When the stage of ulceration has been reached, the large enema sometimes fails to give relief, especially in persons past the middle period of life ; the evacuations do not improve, the pulse becomes quick and feeble, emaciation proceeds rapidly, and the patient soon becomes too weak for anything but pallia tive treatment. In these the large enema must be discontinued, but the small enema, the bael fruit, mild doses of quinine, mineral acids, and opium should be persevered with and may lead to eventual recovery. When the strength admits, large blisters over any obviously thickened part of the large intestine are sometimes decidedly beneficial.

The point at which acute dysentery ends and chronic begins is difficult to mark accurately; but of those cases that have continued under my care, I do not remember any resulting in the chronic form since I began to use large doses of ipecacuanha.

From first to last only a few cases of chronic dysentery have come before me, and these were at, the General Hospital in Calcutta previous to 1861. I treated most of $1 \mathrm{hem}$, if not all, with the large enema, but the records are not now in my possession. The greater number were invalided soldiers, who remained in Calcutta till ships were ready to convey them to England.

The above observations have been drawn from European cases. The treatment of the natives of Iodia is the same as regards medicines by the mouth ; but otherwise it is different, and in the stage of ulceration it is general $y$ unsatisfactory, as they object strongly to enemata of every kind.

Oxford-gardens, North Kensington, W.

\section{ABSCESS OF THE SPLEEN TERMINATING}

\section{FATALLY THROUGH PERFORATION}

\section{OF THE STOMACH.}

BY WM. H. BULL, F.R.C.S. ED., L.R.C.P. LoND, SURGEON TO THE STONY STRATFORD HOSPITAL AND DISPENSARY, ETC.

GEORGE D-, aged forty-two, a groom, married, with five children, presented himself at the Stony Stratford Dispensary on Thursday, Dec. 29 th, 1851, with the following history.

His family history was very good. Was very healthy as a boy; had never had any illness. At the age of nineteen he entered the army, and was sent wirh his regiment the following year (1861) to India. There he remained for nine years, during which time he suffered from inflammation of the liver, and what he called "the fever," and had several attacks of ague. Was discharged from the army for illhealth, and returned to England early in the year 1850 . While in India he was of very temperate habits, and when discharged received a certificate of extra good character. Up on his return to England he married in 1871, and became teetotaller for the first twelve months, after which be took to drinking, and has been a heavy drinker, more or less, up to the present cime. Since his return from India has often complained of not feeling well, and constantly sufered from pain over the spleen, but has never had a retuin of ague. In 1875 he suffered from a very bad ulcerated throat, which had to be freely cauterised. In 1877 had another attack of the same kind, and shortly after that he suffered from iuflammation of the lacrymal sac; this terminared in an abicess which burst and discharged for many months, aud he got into a very low, weak state. He ultimately picked up auain, aud has enjoyed better health fir the last two or three years. There is no history at all of syphilis, and no traces of that disease. For the last month he his been fetling very ponly, without any definite symptoms; has be n extremely irritalle, and on several occasions most impertinent to his master, his previous behaviour having been most exemplary. 
Present illness.-On Thursday morning, December 29th, 1881, he got up at the usual hour and went to the stables at 6 A.M., feeling very poorly. At 7 A.M., on his way to breakfast, felt very sick, and suddenly vomited (acrording to his statement) at least half a pint of blood. This seemed to relieve him, and he felt better and more comfortable when he walked to the dispensary at 9 A.M. than he had done for some time. He was pale and anæemic and a good deal emaciated. On examining the abdomen, in the epigastric region immediately below and slightly to the left of the ensiform appendix there was a spot the size of sixpence, tender only on great pressure; the rest of that region was perfectly free from pain. The liver extended to the lower border of the eleventh rib. The spleen was apparently of normal size, and no pain or discomfort was experienced on pressure in that region. The thoracic organs were all perfectly healthy. The pulse was quiet, regular, rather weak, 76 per minute. Bowels constipated, and had been so during the last few days. He was ordered immediately to bed, with nutritious liquid diet (cold), and ice to suck ad libitum. Perchloride of iron, with morphia, was prescribed. On his return home that morning, contrary to orders, he went to the stables and attempted work, but, feeling so weak in the afternoon, was compelled to go to bed. Feeling still very poorly, he remained in bed the two following days (Dec. 30th and 31st), but got up on the third day (Jan. 1st, 1882), and being much better in all respects, went to work on Jan. 2nd, having had no pain during the last three days.

Jan. 3rd: Went to work as usual in the morning, but was so cold and thoroughly exhausted that at midday he went home and retired at once to bed. -4 th : Passed a comfortable night, but woke early, feeling very sick, and at 7 A. M. vomited quite ten ounces of blood. Ice was freely given, and the usual treatment resorted to, after which he felt very comfort. able. About 9 A. H. passed a very copious stool composed principally of blood. Nausea came on again in the afternoon, and at 3 P. M. vomited at least a pint of blond, after which he experienced considerable relief.-5th: Passed rather a restless night. Has had no sickness or nausea at all to-day, but complains bitterly of dreadful exhaustion and prostration with a good deal of troublesome headache; bowels acted once, composed of fæces and blood; has taken nourishment well-6th: Passed a very restless night, being a little delirious at times. Early in the morning he had a severe rigor, which lasted twenty minutes; after the rigor had passed of he felt very sick, and suddenly vomited a pint of blood, which gave intense relief. In the middle of the day two large solid lumps of blood-clot passed the bowels. In the even ing had another rignr similar to that in the morning; but this was not followed by nausea.-7th: Passed a better night but is very weak and prostrate; in the morning felt very sick and vomited ten ounces of blood, principally in large clots; this gave considerable relief, and he felt comfortable for the rest of the day.-8th: Passed a comfortahle night At $100^{\prime}$ clock 1 .M. was seized with a most severe rigor lasting over twenty minutes, which left him so utterly exhansted that he never rallied, and in spite of all treatment got rapidly worse and died at 10 P.M., being conscious up to the last few moments of his life.

Necropsy of body, thirty-six hours after death.-Body a cood deal emaciated, but free from marks and scars. Examination of abdomen: The liver was somerwhat under normal size; the peritoneum covering it was more or less adherent throughout, especially on its upper surface, and in parts there were firm adhesions to the under-surface of the diaphragm. The organ was pale and firm, presenting on section a waxy, and in parts a somewhat nutmeg, appearance. On removing the stomach an abscess was found, the size of a small orange, in close relationship with the splenic extremity. This abscess was bonnded in front by the splenic end and posterior surface of the stomach; on the outer, or left, side by the lower end of the spleen; below by the pancreas. It had perforated the stomach just where the splenic extremity and pos'erior surfice meet, in four places; one of them freely admitted the index finger, two others admitted the little finter, and the fourth the top of a penholder. The lower part of the largest perforation was much thickened, and seemed to be in a most acute stage of ulceration. A medium-sized branch of the splenic artery, which ran by its side (on the posterior surface of the stomach), presented a perforation large enough to admit a very small pocket-case director : this perforation of the artery was situated just inside the abscess cavity. The abscess contained about an ounce of thick, dark, grumous matter. The mucous membrane of the stomach adjacent to these perforations was very vascular, and the veins gorced with blood, but that covering the rest of the organ was of natural colour, though very anomic. The stomach contained about ten ounces of dark, thick grumous matter, the same as that found in the abscess; it was about the consistence of cream. The spleen was soft and pulpy, and almost broke down on removal ; its substance throughout was of a deep brick-red colour, and seemed to present one homogenfous masa, which was of about the consistence of brain matter. Its lower part was entirely disintegrated, and in astate of ulceration, forming the outer boundary to the abscess wall. The pancleas was healthy; at the splenic end its upner surface was thickened, and enterce into the formation of ihe ahscess. The kidneys were of normal size, very pale, but quite lealtby. The cap-

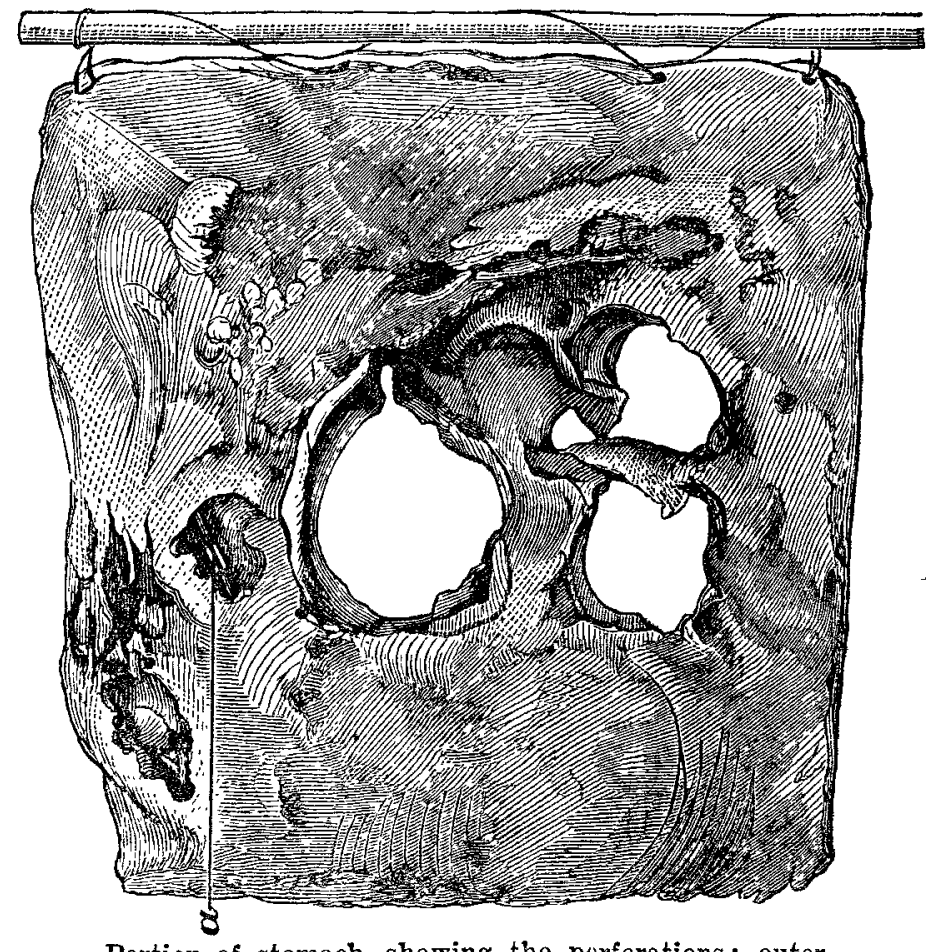

Portion of stomach, showing the perforations; outer surface; $a$ is a glass rod nassed through the artery at the seat of perfnration, the tissues surrounding which have been dissected sufficiently to expose the artery.

sules were easily removed. All the other organs were found perfectly healthy. The head, at the request of the filiends, was not examined.

Remarlis. - This case seemed to be clearly one of "ulcer of the stomach, with death from perforation." The appearance of the patient, his emarinte! condition, his aue and history in general male me struncly sustect hat the nulceration was of a malignant type. The pritinortar exauination, however, showed that perforation was tocontury to abscess in the spleen. This abses in perforatiog the stomach from without inwards hod also pertora'ed an artery; thus the cavity had been aeing as a reservoir for the blood, which was discharced thence into the somach, and this accounted, no doubt, for the somewhat long intervals between the vomitings of blond. With regard to the etiology, it is not improbable that hatmorhagic infarition occurred during one of the patient's attacks in India, which had remained latent up to the fatal ilmess, and that consecutive ioflammation and suppuration of the spleen were now accelerated by his intemperate habits and failing health.

APOTIECARIES' HALT ON InMLAND. - The following office-bearers have beot elcked tur the ensaing year:Governor: Thoms Collins, Denaty Guverner: $R$, Mont-

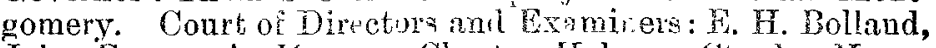
John Evans, A. Harvey, Charles Julmes, Charles Henry Leet, Charles Frederitk Inore, Henry P. Nolan, Richard O'Flaherty, Edward O'Nei!I, Georre Bolster Owens, John Ryan, James Shaw, and Gerroe Wyse. Rapresentative on the General Medical Council : Thomas Collins.

SANiTARY INSTITUTE of Gre.tT BRITIN. - The fifth Autumn Congress and Sanitary Mxhibition of this institute will be held at Newcastle-apon-Tyue on Septeniner 26 th to 30th, under the presidentship of Captniv Donurias Galton, R.E., C.I., F.R.S. Prof, de Chanmont. M.D., F.R.S., has consented to give a lecture to the Congress. 